\title{
CRIMINOLOGY GRADUATES IN THE PRACTICE OF THEIR PROFESSION: AN ANALYSIS OF EMPLOYERS' FEEDBACK
}

\author{
Shirley P. Ayeo-eo ${ }^{1}$, Floralyn L. Doquilla ${ }^{2}$ \\ ${ }^{1,2}$ Nueva Ecija University of Science and Technology \\ Cabanatuan City, Nueva Ecija
}

Article DOI: https://doi.org/10.36713/epra9146

DOI No: 10.36713/epra9146

\begin{abstract}
The main purpose of this study is to determine the employers' feedback in the performance of NEUST criminology graduates in the practice of their profession.

This study made use of a descriptive-quantitative-qualitative survey technique. The study was conducted in the different agencies of the law enforcement with in Nueva Ecija and nearby provinces area where graduates were employed or assigned, specifically, Philippine National Police (PNP), Bureau of Fire Protection (BFP), Philippine Army (PA), Universities and Colleges within Nueva Ecija, and Private Sector.

Based on the findings, employers were very much impressed with the performance of the NEUST criminology graduates as can be seen from their positive responses during the conduct of the study.
\end{abstract}

\section{INTRODUCTION}

"Let a man practice the profession which he best know" - Marcus Tullius Cicero, true enough that man should practice a profession that caters his knowledge and skills, an in depth background on his profession will make him love and understand his role. In the law enforcement profession, this requires a wellfounded foundation in diverse aspects such as; physically, morally, emotionally and psychologically.

Criminology graduates spend years of learning and surpass the challenging Criminologist Board Examination in order to join the law enforcement organization. Since day one in a criminology school, the desire to belong to the uniformed personnel is buried in every criminology students' heart, along with the heartbreaking and inspiring stories behind their innocent minds. Hence, their performance in the practice of their profession is immeasurable.

According to the Australian Industry Group (2006), the demand for higher levels of skills includes frequent skill updating, strong soft skills, and technical skills. According to the report, over $90 \%$ of employers seek employees that are flexible and adaptable, willing to learn on the job, team players, technically capable, and committed to excellence (Thompson et al, 2008). Employers would be able to respond to industry developments if they had a trained and adaptable workforce. Employers, on the other hand, have expressed concern that they are unable to find graduates with the necessary abilities (Hesketh, 2000)

According to Yen et al., there are a few areas where graduates are unable to meet the expectations of their employers. Skills such as critical thinking, problem-solving, and the capacity to apply disciplinary knowledge and concepts in the workplace are viewed as essential areas that need to be addressed. Managing time, speaking/oral communications abilities, and having excellent interpersonal skills were among the top five skills identified as important or extremely important by both employers and alumni, according to Holtzman et al.

Whatever character or work attitude they portray in accomplishing their tasks would always reflect on the institution where they obtained the 
college degree. Graduates are considered significant part on building the image and reputation of the university or college. Therefore, the evaluation of the graduates from the employers serves as feedback mechanism where the institution can develop new strategies on how to improve the attributes of its graduates.

The Nueva Ecija University of Science and Technology (NEUST) is the only state university in the City of Cabanatuan. It is seated in the heart of the city with numerous campuses within the province of Nueva Ecija that offers quality programs. The College of Criminology was created on 2008 through Board resolution No.128-A by the Board of Regents of NEUST and was nestled in Sumacab Campus, Sumacab Sur, Cabanatuan City.

Criminology graduates were lauded for their board examination performances through the years. Tracer studies revealed that voluminous graduates have joined the different law enforcement agencies in the region and in Luzon such as the PNP, BJMP, BFP, Security Industry, Universities and Colleges and private industries.

Their success brings honor to the university; their failure is also the failure of the university especially the college. In this view, the researchers find it significant to follow their tracks and determine how they perform in the practice of their profession. Gathering their employers' feedback would give us data to identify the strengths and weaknesses of our graduates. Also, the result of this study would help the college identify gaps on the teaching in the four corners of the classroom to the real mac coy of enforcement. With this, the college can formulate revisions on their curriculum that would best mold our students that are globally competitive.

\section{OBJECTIVES OF THE STUDY}

The objective of the study is to determine the employers' feedback in the performance of NEUST criminology graduates in the practice of their profession. Further, it also aims to seek employer's ratings on criminology graduates performance in the practice of their profession, in terms of; attendance, attitude, discipline, integrity, and loyalty.

\section{STATEMENT OF THE PROBLEM}

This study aims to determine the employers' feedback in the performance of NEUST criminology graduates in the practice of their profession. Specifically it sought to idenify the following:
1. What is the employer's rate on criminology graduates in the practice of their profession:
a.Attendance
b.Attitude
c.Discipline
d.Integrity
e.Loyalty

2. What are the Employers' Feedback to the NEST Criminology graduates?

\section{Definition of Terms \\ Criminology Graduates. In this study, it refers to the graduates of the Nueva Ecija University of Science and Technology, Cabanatuan City Nueva Ecija.}

Employers' Feedback. In this study, it refers to the data gathered in terms of attendance, attitude, discipline, integrity and loyalty of NEUST Criminology graduates.

Practice. In this study, it refers on how the Criminology graduates perform thier job assigned to them.

Profession. It refers to the specialization of the NEUST Criminology graduates.

\section{METHODOLOGY}

In this study, the researchers used descriptivequantitative-qualitative survey technique. The study was conducted in the different agencies of the law enforcement with in Nueva Ecija and nearby provinces area where graduates were employed or assigned, specifically, Philippine National Police (PNP), Bureau of Fire Protection (BFP), Philippine Army (PA), Universities and Colleges within Nueva Ecija, and Private Sector. The immediate superiors and supervisors were identified as respondents as the best source of information to address the objectives of the study. The conduct of the study was coordinated with the different identified agencies. A self-made questionnaire was used in data gathering online through Google form for the part I of the questionnaire and a phone call interview for the second part of the questionnaire. Moreover, the content validity of the questionnaire will be validated by a tool validator. The responses to the questionnaires were treated through percentage, frequency counts, ranking, and were collated. The researchers also respected the privacy, confidentiality, and anonymity of the participants. 


\section{RESULTS AND DISCUSSION}

The Employer's Ratings on Criminology Graduates in the Practice of their Profession

Attendance

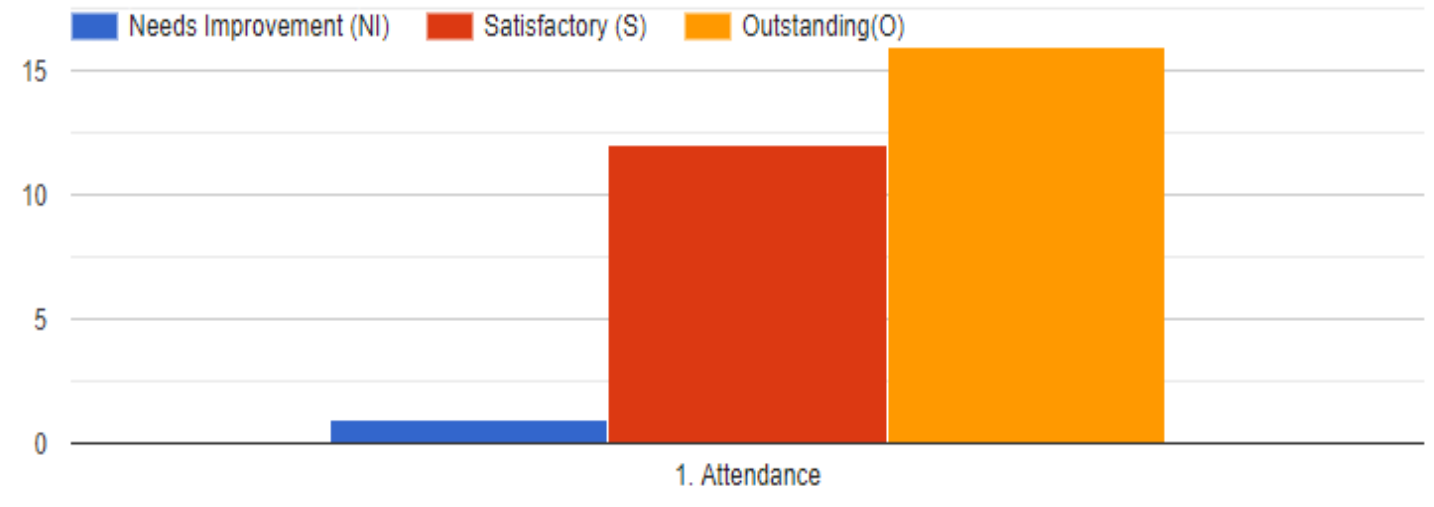

Figure 1

Note: In can be gleaned that criminology graduates performed well as to their attendance as they were rated as satisfactory and outstanding, though it can also be seen that there was a rating of needs improvement nevertheless, it does not affect the very good overall rating since only 1 respondent rated NI out of 30 respondents. 
Attitude

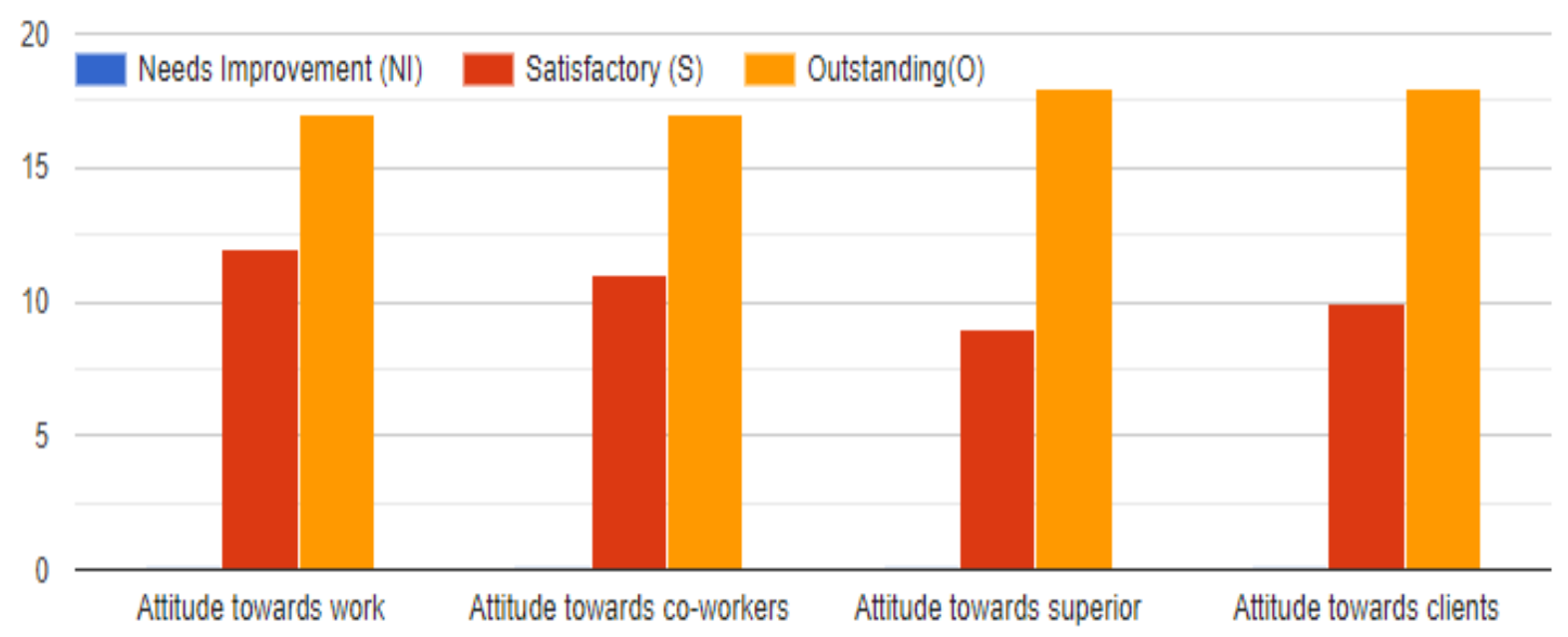

Figure 2

Note: It can be gleaned that NEUST criminology graduates possesses positive attitude in dealing with their task, peers, superiors and clients as they got a majority of satisfactory and outstanding rating from all of the respondents.

Discipline

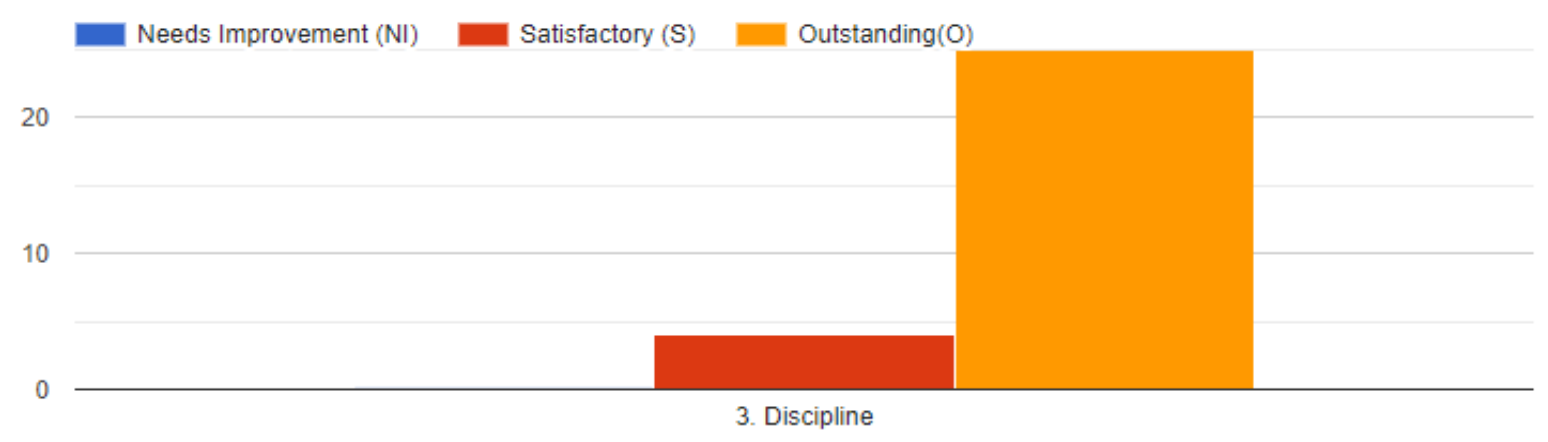

Figure 3

Note: This implies that employers were satisfied with the discipline displayed by the NEUST criminology graduates in the practice of their profession. 


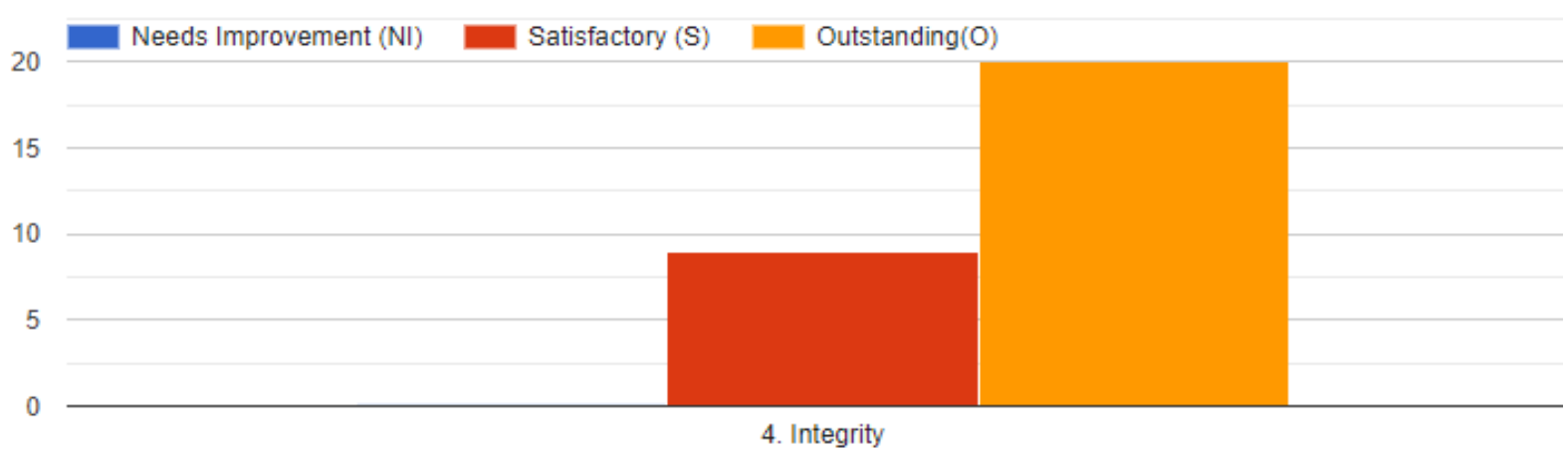

Figure 4

Note: It can be seen that employers appreciate the integrity of the graduates as can be seen by their ratings.

Loyalty

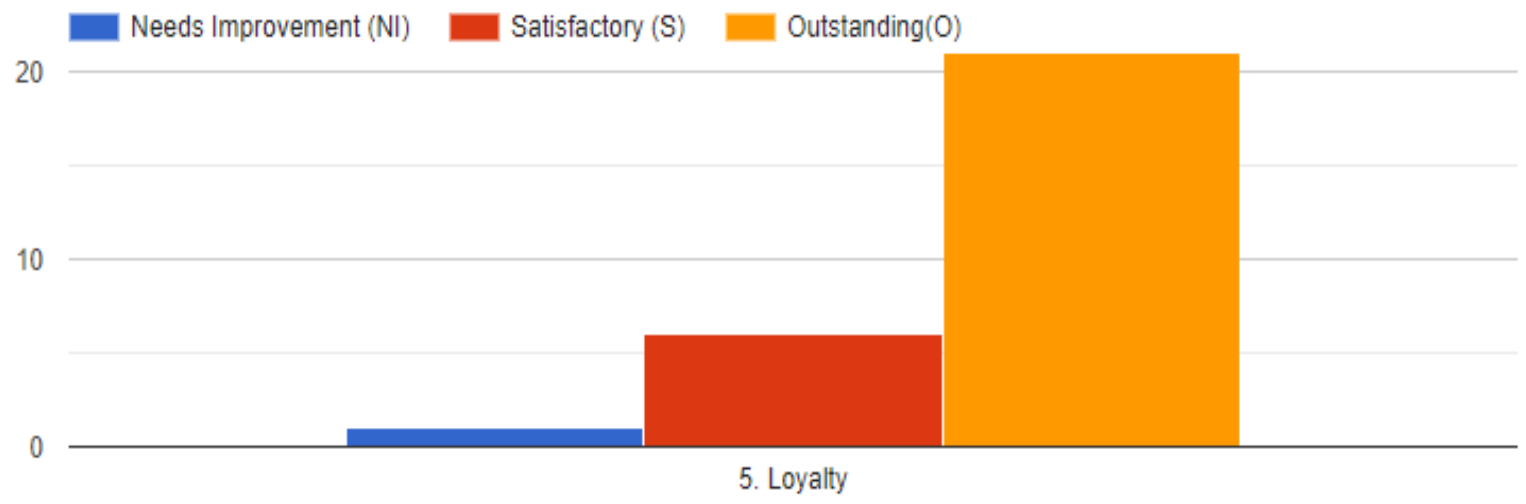

Figure 5

Note: The figure implies that majority of the employers believed that NEUST criminology graduates were loyal as can be seen with the majority rating as outstanding, though there's still a needs for improvement.

\section{The Employers' Feedback to the NEUST}

\section{Criminology Graduates}

Employer's feedbacks are valuable to employees as a means for monitoring or for improvement. Employees can also be reminded if they are performing well or not. In every organization, they have their own mechanics in assessing their employees' performance. In schools and universities it is also important to determine the performance of their graduates through employers' feedback to assess the effectiveness and efficiency of their programs.

The study revealed that employers were very much impressed with the performance of the NEUST criminology graduates as can be seen from their positive responses during the conduct of the study.

Bureau of Fire Protection respondents positively described the NEUST criminology graduates and said that "NEUST Criminology is a competitive school in Region 3, which produce best students in 
their field of work" this was corroborated by the answer of the second respondent from the bureau as "very impressive" and others answered "good and outstanding".

Private institutions such as; schools, universities, malls, construction firms, and security industries affirmed the positive attitude of the NEUST criminology graduates and answered our queries as "Well educated, pleasing personality, flexible and fast learner", "High Discipline", "On time wherevers there's a meeting or at work", "exhibits a positive outlook and attitude in the work", "So far, they are appreciative on the skills and contribution of the employee towards the department and the school as a whole".

"Very reliable", the NEUST criminology graduates were also labeled as such by the respondent from the Philippine Army, pointing out a positive description on their subordinates who were graduates of the university.

Philippine National Police respondents also affirmed the positive responses from other agencies, saying among others that "Criminology Graduates from NEUST are knowledgeable about police work even in field and office work", this was corroborated by another respondent saying "NEUST Graduates have a good Moral Character", it was also followed up by another respondent emphasizing that "Well educated and competent", other respondents also answered "Highly discipline", and "Street wise".

\section{CONCLUSION AND RECOMMENDATIONS}

The researchers conclude that employers were satisfied and happy with the performance of NEUST criminology graduates as to their attendance, attitude, discipline, integrity and loyalty. The NEUST criminology graduates were also positively described by their employers from different agencies.

It is then recommended that the university more specifically the college of criminology should continue and strengthen their program to produce quality graduates, as well a deeper study be conducted to identify other concerns of criminology graduates in the practice of their profession.

\footnotetext{
REFERENCES

Online Sources

1. Jocelyn B. Cruz. "Choosing an Ideal Graduate Education: The Nueva Ecija University of Science and Technology Experience", Open Journal of Social Sciences, 2018

2. research.lpubatangas.edu.ph

3. www.apjmr.com

4. marinduquenews.com
}

5. docplayer.net 